\title{
An Early Comparative Analysis of the Use of Autograft Versus Allograft in Anterior Cervical Discectomy and Fusion
}

\author{
Sang Yong Kim, Ki Seok Park, Sung Sam Jung, Seong Young Chung, \\ Seong Mim Kim, Moon Sun Park, Han Kyu Kim \\ Department of Neurosurgery, Eulji University College of Medicine, Daejeon, Korea
}

Objective: The purpose of this study is to verify the usefulness of autograft versus allograft in the radiographic and clinical outcome in early period after the surgery.

Methods: We performed a retrospective review of 38 patients who had undergone one- or two-level anterior cervical discectomy and fusion (ACDF) with rigid anterior plate fixation from March 2006 to May 2009. Interbody graft materials were iliac autograft $(n=17)$ or with allograft $(n=21)$. Fusion rate and graft collapse rate were assessed by radiographic analysis and clinical outcome was based on Odom's criteria.

Results: In autograft group, 13 patients achieved successful bone fusion (65\%), whereas 7 patients (31.8\%) in allograft group. There was statistically significant between two groups $(p<0.05)$. Comparing immediate postoperative radiograph with last followup, the mean graft collapse was noted $1.3 \mathrm{~mm}(15.5 \%$ change) in autograft group, whereas $2.0 \mathrm{~mm}(24.7 \%$ change) in allograft group. There was no statistically significant collapse rate in autograft group $(p>0.05)$, but statistically significant in allograft group ( $p<0.05$ ). Clinical outcome was excellent or good in $94.1 \%$ in autograft group, and $90.5 \%$ in allograft group.

Conclusion: In study, anterior cervical interbody fusion with an allograft got a result of lower fusion rate and higher collapse rate compared with autograft in early period after surgery, and clinical outcome showed similar results in both groups.

Key Words: Cervical Vertebrae $\cdot$ Spinal Fusion $\cdot$ Autograft $\cdot$ Allograft

\section{INTRODUCTION}

Anterior cervical discectomy and fusion (ACDF) is a common surgical procedure used in the treatment of many cervical spine disorders; herniated discs, spondylosis, fractures, and neoplastic lesions ${ }^{15}$. Since initially reported in 1955 by Robinson and Smith ${ }^{19)}$, ACDF has become an accepted procedure for decompression of nerve root, spinal cord and spinal stabilization in the treatment of above diseases.

Fusion is affected by the types of graft. The selection of the appropriate graft substrate is imperative to achieve successful bone fusion and an optimal clinical outcome $e^{20)}$. The gold standard for cervical fusion material is autologous iliac crest bone, however many complications of autograft substrates

- Received: April 20, 2012 - Revised: August 20, 2012

- Accepted: September 25, 2012

Corresponding Author: Ki Seok Park, MD

Department of Neurosurgery, Eulji University Hospital, 1306 Dunsan-dong, Seo-gu, Daejeon 302-799, Korea

Tel: +82-42-611-3442, Fax: +82-42-611-3444

Email:ks3432@eulji.ac.kr have been reported ${ }^{212)}$. The harvest site for autogenous iliac crest bone grafts is associated with an amplified risk of morbidity, operative time, hospital stay and postoperative recovery ${ }^{21}$. On the other hand, the allogenic graft substitutes have shown to reduce postoperative morbidity and shorten hospital stay ${ }^{11,26}$. Although it is known that autograft increases the fusion rate and decreases the collapse rate, a debate still exists between the efficacy of autograft versus allograft and its relationship to clinical outcome in $\mathrm{ACDF}^{20)}$.

The purpose of this study is to determine efficacy of autograft versus allograft in radiographic and clinical outcome in early period after operation.

\section{MATERIALS AND METHODS}

From 2006 to 2009, thirty-eight patients underwent oneor two-level cervical anterior fusion with rigid anterior plate fixation. Among the patients, 17 patients (44.7\%) underwent ACDF with autograft bone and 21 patients (55.3\%) received with allograft bone. Three patients had two- level ACDF in the autograft group and one patient in the allograft group. There 
Table 1. Demographics of patients and level of cervical operation

\begin{tabular}{llll}
\hline \hline & Autograft roup & Allograft group & p-value \\
\hline $\begin{array}{l}\text { Mean age (years) } \\
\text { Sex }\end{array}$ & $51.9 \pm 13.21$ & $54.3 \pm 13.97$ & $>0.05$ \\
$\quad$ male & $14(82.4 \%)$ & $12(57.1 \%)$ & \\
$\quad$ female & $3(17.6 \%)$ & $9(42.9 \%)$ & \\
Mean follow-up & $12.4 \pm 3.37$ & $12.8 \pm 2.02$ & $>0.05$ \\
period (months) & & & \\
BMl & $24.1 \pm 3.93$ & $23.5 \pm 2.60$ & $>0.05$ \\
BMD & & & \\
male & $9(-1.1 \pm 0.81)$ & $10(-0.9 \pm 1.62)$ & $>0.05$ \\
female & $2(-0.7 \pm 0.78)$ & $6(-0.4 \pm 1.08)$ & $>0.05$ \\
Smoking & $7(41 \%)$ & $8(38 \%)$ & \\
Operated cervical & & & \\
level & & & \\
C3-4 & $2(11.8 \%)$ & $3(14.3 \%)$ & \\
C4-5 & $4(23.5 \%)$ & $6(28.6 \%)$ & \\
C5-6 & $6(35.3 \%)$ & $7(33.3 \%)$ & \\
C6-7 & $2(11.8 \%)$ & $4(19.0 \%)$ & \\
C3-5 & $1(5.8 \%)$ & $1(4.8 \%)$ & \\
C4-6 & $2(11.8 \%)$ & $0(0.0 \%)$ & \\
\hline Total & 17 & 21 & \\
\hline B & 17 & & \\
\hline
\end{tabular}

$\mathrm{BMI}=$ body mass index $\left(\mathrm{kg} / \mathrm{m}^{2}\right)$

$\mathrm{BMD}=$ bone mineral density ( $\mathrm{t}$-score)

were 14 males and 3 females ranging in age from 29 to 78 years (mean age, 51.9 years) in autograft group, 12 males and 9 females ranging in age from 23 to 72 years (mean age, 54.3 years) in allograft group. The mean follow-up period of these patients was 12.4 months (range, 11 to 20 months) in autograft group, 12.8 months (range, 10 to 17 months) in allograft group. Bone mineral density (BMD), body mass index (BMI), status of smoking and operated cervical level were compared, and $\mathrm{BMD}$ was performed only in patients above age 50 (Table 1).

One senior surgeon and junior surgeon performed all procedures by means of a standard Smith-Robinson anteromedial approach to the cervical spine and using microsurgical technique. The graft substrates were fashioned and countersunk into the interspace after disc removal. Preparation of the vertebra endplates was achieved by cartilage removal with a curette and the endplate for graft insertion in all patients. Autografts were harvested with a low-speed oscillating saw at the anterior iliac crest. Allografts were freeze-dried iliac crest bone. Application of an anterior variable type cervical plate $\left(\right.$ MAXIMA $^{\mathbb{R}}$ ) was performed in all patients without using distractor during the surgery. Usage of non-steroidal anti-inflammatory drugs (NSAIDs) was within one month after the surgery and patients were kept in a Philadelphia collar for 4 weeks after the surgery.

For the evaluation of interbody fusion, the last follow-up plain radiographs were used. The fusion rate was assessed by Bridwell interbody fusion grading system ${ }^{4}$ (Table 2), and we
Table 2. Bridwell interbody fusion grading system

\begin{tabular}{|c|c|}
\hline Grade & Description \\
\hline I & Fused with remodeling and trabeculae present \\
\hline$\|$ & $\begin{array}{l}\text { Graft intact, not fully remodeled and incorporated, but no } \\
\text { lucency present }\end{array}$ \\
\hline III & $\begin{array}{l}\text { Graft intact, potential lucency present at top and bottom } \\
\text { of graft }\end{array}$ \\
\hline IV & Fusion absent with collapse/resorption of graft \\
\hline
\end{tabular}

considered grade I or II as successful fusion. The graft collapse rate was evaluated comparing the initial graft height with last follow-up graft height in the plain radiographs. The graft collapse height was measured by the distance connecting the line drawn on the upper and lower end-plates of the fusion segment and the center of the superior and inferior end-plates. Clinical evaluations were assessed with the outcome based on the Odom's criteria ${ }^{16}$. Excellent or good outcome was considered satisfactory.

The data was analyzed by SPSS (version 10.0) statistical software. Statistical analysis was performed with paired T-test, chi-squared test, and Mann-Whitney U-test. Statistical significance was established at $\mathrm{p}<0.05$.

\section{RESULTS}

Forty two interspaces were fused in 38 patients: 20 levels with autograft bone in 17 patients ( 3 patients had two-level ACDFs), 22 levels with iliac crest allograft bone in 21 patients (1 patient had two-level ACDFs). Statistical analysis of the age, follow-up period, BMI, BMD, and status of smoking between two groups showed no significance $(p>0.05)$ (Table 1$)$.

The overall radiographic successful fusion rate in our series was $47.6 \%$, based on the Bridwell interbody fusion grading system. $65 \%$ of the patients with autograft achieved successful fusion, whereas only $31.8 \%$ of the patients with allograft achieved successful fusion (Fig 1). Statistical significant difference was noted between autograft and allograft in the fusion rate $(\mathrm{p}<0.05)$ (Table 3).

The mean fused interspace height was less well maintained in cases using allograft bone than autograft bone. The mean collapse in cases using allograft was $2.0 \mathrm{~mm}$ ( $24.7 \%$ change) between the initial and last follow-up radiograph, a statistically significant difference $(p<0.05)$ (Fig. 2). Whereas, the mean interspace collapse in cases using autograft was $1.3 \mathrm{~mm}(15.5 \%$ change), which resulted in no statistically significant difference ( $>0.05)$ (Table 4).

The postoperative clinical outcome was assessed in all patients, based on Odom's criteria. Excellent results were reported in $41.2 \%$, good results in 52.9\%, and fair results in 5.9\% 
Table 3. Fusion rate in relation to graft-type by Bridwell interbody fusion grading system. There is statistical significant difference between the two groups $(p<0.05)$

\begin{tabular}{lccccc}
\hline \hline \multicolumn{7}{c}{ Fusion rate } \\
\hline Autograft & \multicolumn{1}{c}{} & \multicolumn{1}{c}{ I } & III & IV & Successful fusion (I+II) \\
Allograft & $6(30.0 \%)$ & $7(35.0 \%)$ & $7(35.0 \%)$ & $0(0 \%)$ & $13 / 20(65.0 \%)$ \\
\hline & $5(22.7 \%)$ & $2(9.1 \%)$ & $15(68.2 \%)$ & $0(0 \%)$ & $7 / 22(31.8 \%)$ \\
\hline
\end{tabular}

Table 4. Collapse rate in relation to graft-type

\begin{tabular}{lcccc}
\hline \hline & $\begin{array}{c}\text { Mean } \\
\text { Initial graft } \\
\text { height }\end{array}$ & $\begin{array}{c}\text { Mean } \\
\text { Last follow-up } \\
\text { graft height }\end{array}$ & $\begin{array}{c}\text { Collapse } \\
\text { rate }\end{array}$ & p-value \\
\hline Autograft & $8.4 \mathrm{~mm}$ & $7.1 \mathrm{~mm}$ & $15.5 \%$ & $\mathrm{p}>0.05$ \\
Allograft & $8.1 \mathrm{~mm}$ & $6.1 \mathrm{~mm}$ & $24.7 \%$ & $\mathrm{p}<0.05$ \\
\hline
\end{tabular}

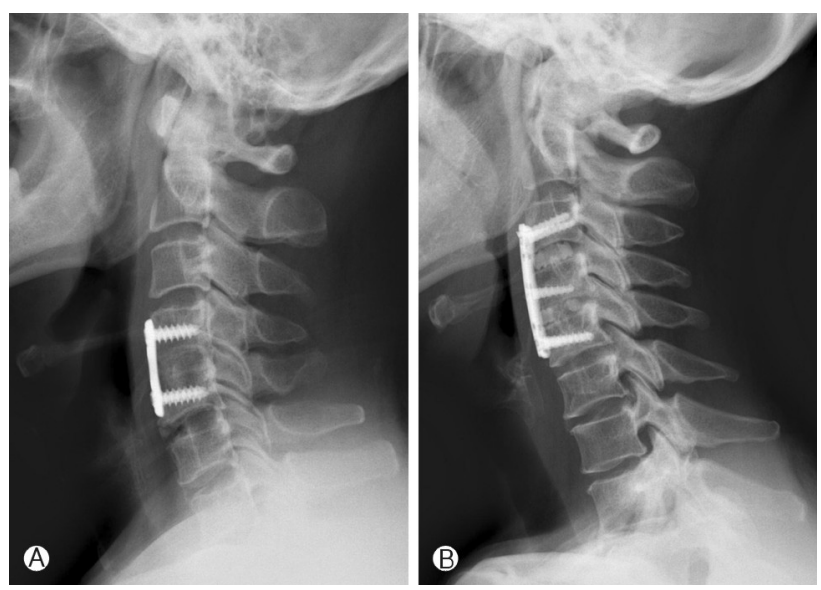

Fig. 1. (A) 10 months postoperative lateral radiograph of a 47 years old male patient who underwent one-level ACDF (C4-5) with autograft (Bridwell fusion grade I). (B) 12 months postoperative lateral radiograph of a 54-year-old female patient who underwent twolevel ACDF (C3-4, C4-5) with allograft (Bridwell fusion grade III).

in the autograft group. And excellent results were reported in $38.1 \%$, good results in $52.4 \%$, and fair results in $9.5 \%$ in the allograft group. No poor results were noted in both groups (Table 5). No other intraoperative, postoperative, or radiographic complications were noted in this series.

\section{DISCUSSION}

Since the 1950s, ACDF has been a widely accepted procedure for the treatment of degenerative disc disease and spondylosis of the cervical spine $e^{2,3,7,10,12,20,24)}$. Cervical interbody fusion is used after surgery to help minimize postoperative morbidity, maintain cervical spinal alignment, eliminate potential instability, and preserve interspace height and angulation ${ }^{3)}$. Cervical spine interbody fusion has achieved favorable clinical outcomes and

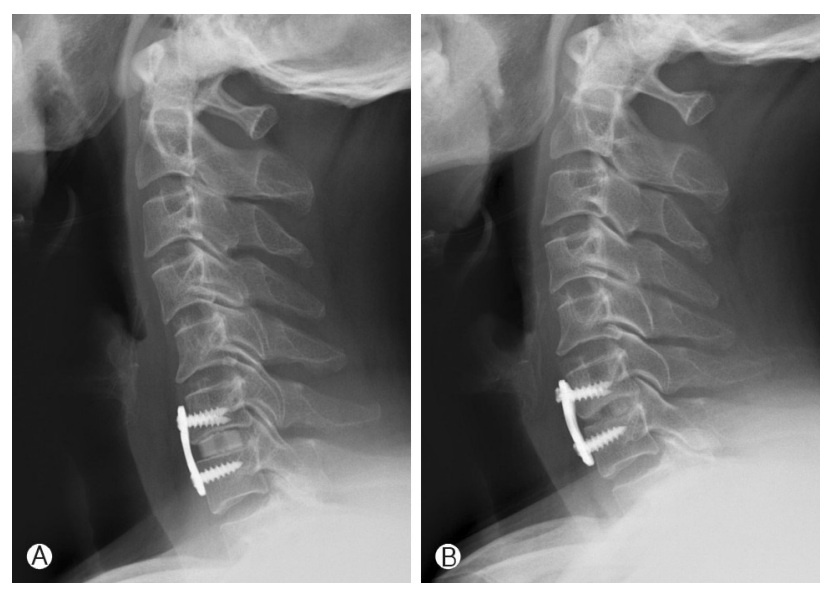

Fig. 2. A and B: (A) Immediate postoperative radiograph. (B) 10 months follow uppostoperative lateral radiograph. A 57 years old male patient who underwent one-level ACDF (C6-7) with allograft. Immediate postoperative radiograph at $9 \mathrm{~mm}$ interspace graft height. 10 months postoperative radiograph showed $5 \mathrm{~mm}$ interspace graft height, with $44.4 \%$ decreased collapse rate.

is the gold standard for treating patients with degenerative disc disease and spondylosis. Robinson et al. ${ }^{19)}$ reported the first large series of patients with cervical radiculopathy treated with anterior interbody fusion, in this series $73 \%$ of the patients achieved good or excellent outcomes. Other authors have reported clinically good to excellent results in $80-90 \%$ of cases $^{7,10}$.

Bone healing and fusion at an interbody fusion site are dependent on three main factors. There are recipient site condition, fusion substrate, and regional and systemic host features ${ }^{3)}$. Among these, selection of the appropriate graft substitutes to optimize fusion rate and bone healing is essential. Graft substitutes have been developed including xenograft, allograft, cages, ceramics, bioabsorbable implants that may produce as comparable fusion rates as autograft bone ${ }^{2}$. Autologous iliac crest graft and freeze-dried allograft are commonly used in clinical practice during ACDF.

Bone healing occurs through the mechanisms of osteogenesis, osteoinduction, and osteoconduction ${ }^{1,24)}$. Osteogenesis requires live bone cells, mature osteoblasts and osteocytes, that remain viable after transplantation by diffusion in the graft ${ }^{6,15)}$. Autogeneic grafts can participate actively in bone healing through osteogenesis, whereas allogeneic bone contains no live 
Table 5. Clinical results in relation to graft-type by the Odom's clinical outcome classification

\begin{tabular}{lcrrrr}
\multicolumn{5}{c}{ Clinical } & \multicolumn{1}{c}{ outcome } \\
\hline & Excellent & Good & Fair & Poor & Successful treatment \\
\hline Autograft & $7(41.2 \%)$ & $9(52.9 \%)$ & $1(5.9 \%)$ & $0(0 \%)$ & $16 / 17(94.1 \%)$ \\
Allograft & $8(38.1 \%)$ & $11(52.4 \%)$ & $2(9.5 \%)$ & $0(0 \%)$ & $19 / 21(90.5 \%)$ \\
\hline
\end{tabular}

cells, and thus does not promote bone healing through osteogenesis $^{18)}$. Osteoinduction, the ability of the graft to stimulate adjacent bone at the recipient site to initiate vascular ingrowth and the transformation and recruitment of osteogenic cells is a property unique to organic bone substrates. The osteoinductive capability of allograft bone is thought to be less than that of autogeneic bone ${ }^{13,18)}$. Osteoconduction is the growth of bony tissue into the structure of graft site. Little controversy exists over the ability of both autogeneic and allogeneic bone to provide osteoconduction ${ }^{1,25)}$. In brief, allograft substrates are considered highly osteoconductive, weakly osteoinductive, and not osteogenic property. For this reason, autograft is a better interbody fusion substrate than allograft substrates biologically.

Autograft fusion rates after cervical interbody fusion have been reported to range between $73 \%$ and $97 \%$. In comparison, allograft fusion rates have been reported to be between $54 \%$ and 94\% $\% 3,9,12,16,27,28)$. Most studies showed better to similar fusion rate in autograft compared to allograft. In our cases, autograft showed 65\% successful fusion rate and 31.8\% in allograft in short term follow-up period. Reason for such results are related to weak osteoinductive and poor osteogenic property in allograft which lead to prolonged fusion time after the surgery ${ }^{12)}$.

In addition to a high fusion rate, successful treatment depends on maintenance of interspace height and angle ${ }^{3,28)}$. Maintenance of graft height influenced the rate of bone resorption. The reduced compressive strength, caused by a more rapid rate of bone resorption, may exacerbate graft collapse ${ }^{11)}$. Pelker et $\mathrm{al}^{17)}$ found that freeze-dried iliac crest graft material had a 10\% loss of compression strength and a $70 \%$ reduction in torsion strength compared to autogeneic iliac crest bone. An average interspace collapse rate $14 \%$ to $24.4 \%$ in the autograft group, and $24 \%$ to $50 \%$ in the allograft group were reported $^{3,5,28)}$. In our study, the collapse rate in the autograft group $(15.5 \%)$ was less than in the allograft group (24.7\%). The mean fused interspace height was less well maintained in cases using allograft fusion substrate than autograft bone.

Although autografts had higher fusion rate and lower interspace collapse rate than allografts, they had disadvantages, such as graft harvesting complications, including hematoma, infection, lateral femoral cutaneous nerve injury, and persistent donor site pain, fracture of graft bone, prolonged operation time, and longer hospitalization ${ }^{12)}$. Graft harvesting complications have been reported with a rate of $15-20 \%$ of patients undergoing $\mathrm{ACDF}$ with autograft ${ }^{8,18)}$. In our cases, there was no complication related to graft harvesting. Although allograft group showed lower fusion rate and higher collapse rate compared with autograft group, these factors did not effect the clinical outcome. In our study, $94.1 \%$ of patients in autograft group achieved satisfactory results, compared with $90.5 \%$ of patients in allograft group. Likewise, other studies reported no significant difference in clinical outcome between both groups ${ }^{24)}$.

There are some limitations in our study. The ratio of gender in two groups is different, and female gender can show the difference in BMD score and it can influence the fusion rate and collapse rate. However, there was no statistically significance in female BMD between both groups. Also there was limitation of interpreting the results of bone fusion through only simple radiographs and the number of enrollment was too small to represent the accurate outcome. For more precise outcome, the longer follow-up result of postoperative patients with various radiographic images such as Computed Tomography (CT) and larger number of patients would be necessary. Finally, freeze-dried allograft bone was diminished in resistance to bending and torsion compared to autograft bone and with less probability, the risk of possibility of AIDS virus infection with weakened immunogenicity should be considered.

\section{CONCLUSION}

In practically, autologous iliac crest graft and freeze-dried allograft are commonly used in ACDF. Although autograft is ideal graft substrate for interbody fusion, it has several disadvantages and complications. Allograft demonstrate lower fusion and higher collapse rate compared with autograft in the shortterm follow-up study, but clinical outcome showed similar results in between both groups. Lager number of patients and longer follow-up would be necessary.

\section{REFERENCES}

1. Albrektsson T, Johansson. C: Osteoinduction, osteoconduction and osseointegration. Eur Spine J 10:S96-S101, 2001

2. An HS, Simpson JM, Glover JM, Stephany J: Comparison bet- 
ween allograft plus demineralized bone matrix versus autograft in anterior cervical fusion. A prospective multicenter study. Spine (Phila Pa 1976) 20:2211-2216, 1995

3. Bishop RC, Moore KA, Hadley MN: Anterior cervical interbody fusion using autogeneic and allogeneic bone graft substrate: a prospective comparative analysis. J Neurosurg 85:206-210, 1996

4. Bridwell KH, Lenke LG, McEnery KW, Baldus C, Blanke K: Anterior fresh frozen structural allografts in the thoracic and lumbar spine. Do they work if combined with posterior fusion and instrumentation in adult patients with kyphosis or anterior column defects? Spine 20:1410-1418, 1995

5. Brown MD, Malinin TI, Davis PB: A roentgenographic evaluation of frozen allografts versus autografts in anterior cervical spine fusions. Clin Orthop Relat Res 119:231-236, 1976

6. Burchardt H: The biology of bone graft repair. Clin Orthop Relat Res 174:28-42, 1983

7. Clements DH, O'Leary PF: Anterior cervical discectomy and fusion. Spine (Phila Pa 1976) 15:1023-1025, 1990

8. EspersonJO, Buhl M, Eriksen EF, Fode K, Klaerke A, Krøyer $\mathrm{L}$, et al: Treatment of cervical disc disease using Cloward's technique: General results, effect of different operative methods and complications in 1,106 patients. Acta Neurochir (Wien) 70:97-114, 1984

9. Fernyhough JC, White JI, La Rocca H: Fusion rates in multilevel cervical spondylosis comparing allograft fibula with autograft fibula in 126 patients. Spine 16:S561-S564, 1991

10. Gore DR, Sepie SB: Anterior cervical fusion for degenerated or protruded discs. Spine (Phila Pa 1976) 9:667-671, 1984

11. Jensen WK, Moore TA, Tribus CB, Anderson PA, Zdeblick TA: Use of patella allograft for anterior cervical diskectomy and fusion. J Spinal Disord Tech 22:392-398, 2009

12. Kao FC, Niu CC, Chen LH, Lai PL, Chen WJ: Maintenance of interbody space in one- and two-level anterior cervical interbody fusion: comparison of the effectiveness of autograft, allograft, and cage. Clin Orthop Relat Res 430:108-116, 2005

13. Kaufman HH, Jones E: The principles of bony spinal fusion. Neurosurgery 24:264-270, 1989

14. Khan S, Sama A, Sandhu HS: Bone graft substitutes in spine surgery. Curr Opin Orthp 12:216-222, 2001

15. Martin GJJr, Haid RWJr, Mac Millan M, Rodts GEJr, Berkman R: Anterior cervical discectomy with freeze-dried fibula allograft. Overview of 317 cases and literature review. Spine 24:852-858, 1999

16. Odom GL, Finney W, Woodhall B: Cervical disk lesions. J Am
Med Assoc 166:23-28, 1958

17. Pelker RR, Freidlander GE, Markham TC: Biomechanical properties of bone allografts. Clin Orthop Relat Res 174:54-57, 1983

18. Prolo DJ: Biology of bone fusion. Clin Neurosurg 36:135-146, 1990

19. Robinson R, Smith G: Anterolateral cervical disc removal and interbody fusion for cervical disc syndrome. Bull Johns Hopkins Hosp 96:223-224, 1955

20. Samartzis D, Shen FH, Matthews DK, Yoon ST, Goldberg EJ, An HS: Comparison of allograft to autograft in multilevel anterior cervical discectomy and fusion with rigid plate fixation. Spine J 3:451-459, 2003

21. Schnee CL, Freese A, Weil RJ, Marcotte PJ: Analysis of harvest morbidity and radiographic outcome using autograft for anterior cervical fusion. Spine (Phila Pa 1976) 22:2222-2227, 1997

22. Silber JS, Anderson DG, Daffner SD, Brislin BT, Leland JM, Hilibrand AS, et al: Donor site morbidity after anterior iliac crest bone harvest for single-level anterior cervical discectomy and fusion. Spine (Phila Pa 1976) 28:134-139, 2003

23. Ryu SI, Lim JT, Kim SM, Paterno J, Willenberg R, Kim DH: Comparison of the biomechanical stability of dense cancellous allograft with tricortical iliac autograft and fibular allograft for cervical interbody fusion. Eur Spine J 15:1339-1345, 2006

24. Wang JC, McDonough PW, Endow KK, Delamarter RB: A comparison of fusion rates between single-level cervical corpectomy and two-level discectomy and fusion. J Spinal Disord 14:222225, 2001

25. Wilson-Hench J: OsteoinductionIn Williams DF (eds): Progress in biomedical engineering, Definitions in biomaterials. Amsterdam: Elsevier, Vol 4, pp29, 1987

26. Yoon WS, Cho KS, Park JH, Yoo DS, Huh PW, Kim DS, et al: Clinical outcome of allograft fibular bone filled with autologous bone chips in cervical spinal surgery. Korean J Spine 1:445-449, 2004

27. Young WF, Rosenwasser RH: An early comparative analysis of the use of fibular allograft versus autologous iliac crest graft for interbody fusion after anterior cervical discectomy. Spine (Phila Pa 1976) 18:1123-1124, 1993

28. Zdeblick TA, Ducker TB: The use of freeze-dried allograft bone for anterior cervical fusions. Spine (Phila Pa 1976) 16:726-729, 1991 